\title{
MOBILIZING BIM IN A COLLABORATIVE PROJECT ENVIRONMENT
}

\author{
Bill Collinge $^{1}$ and John Connaughton ${ }^{2}$
}

\begin{abstract}
This paper reports on the application of BIM methods an innovative project in the UK that is pioneering a new form of project insurance (Integrated Project Insurance) that joins project partners together as a virtual company. The paper examines the processes put in place to optimize BIM usage whilst reviewing the problems and issues encountered; the observations of a researcher being combined with the reflections of the BIM Information Manager.

It is noted that mobilizing a comprehensive BIM-centric system is a complex and difficult undertaking, with new roles and responsibilities needing to be created, that put extra pressures on project partners. The positive results of using BIM in a collaborative environment are noted as the findings suggest inclusive contractual arrangements facilitate enhanced BIM use. The insights inform understanding of mobilizing BIM in a collaborative project environment as it is argued that only a fully collaborative project environment can realise the full benefits of BIM.
\end{abstract}

Keywords: BIM, collaboration, Integrated Project Insurance, organization.

\section{INTRODUCTION}

It has been argued that to realize the full potential of BIM, project partners must be free to share and exchange information without fear or hesitation of litigation (Hui, 2013). However, such an approach requires project partners to be bound together contractually, and such arrangements remain rare (in the UK construction industry at least). Whilst there is a trend for more relational type contracting methods, such as project alliancing (Young et al. 2016), such arrangements do not join the whole project team together to achieve mutually beneficial outcomes for every partner. Therefore, whilst commentators such as Demian \& Walters (2014) and Eastman et al. (2008) argue that BIM improves information management processes, the contractual realities enabling such co-operation to happen are often absent from projects. As noted by Gardiner (2016), when quoting Greenwood,

"The last 50 years have shown you 're not going to get collaboration or partnership without full-process integration, because people have to protect their legal position. You can`t expect some whizz-bang system will force people to integrate.” (p.25)

1 Researcher, Construction Management \& Engineering, Whiteknights, University of Reading, Reading, UK, will.collinge@reading.ac.uk

2 Professor of Sustainable Systems in the Built Environment, Construction Management \& Engineering, Whiteknights, University of Reading, Reading, UK, j.connaughton@reading.ac.uk

The project reported here is part of the Innovate UK's (formerly the Technology Strategy Board) Rethinking the Build Process and acknowledgement is made of the financial support provided by that programme. Specific results and their interpretation remain the responsibility of the project team. 
This paper engages with this issue through an exploration of BIM use on a project in the UK that is pioneering a new form of insurance that joins principal partners together under a single, all-embracing insurance product: Integrated Project Insurance (IPI). IPI offers a new way of working on construction projects as it binds together parties (i.e. client; architect; structural engineer; designer; constructor and specialist(s) in a relationship that is mutually beneficial, giving parties a gain/pain share depending on project performance. IPI arguably engenders greater collaboration and establishes an important framework for better BIM achievements. The extent to which IPI facilitates enhanced BIM use is explored through the paper as the realities of mobilizing BIM on a low-medium sized project in the UK is examined.

The paper begins by reviewing the literature relating to BIM and the contractual realities prevalent in the UK industry today. A research method section describes the methodology employed and describes the project and IPI in greater detail. The processes put in place to mobilize BIM in the collaborative project environment are then described; the narrative being supplemented by comments from a BIM Information Manager on the project. A discussion reflects on the issues arising and identifies some lessons learned. A closing conclusion draws the findings of the paper together.

\section{BIM \& CONTRACTUAL REALITIES}

The advent of BIM has been heralded as the key development that will bring improvements to construction project information management (Eastman et al., 2008), enhancing design, delivery and maintenance of facilities and bringing greater stakeholder involvement (e.g. Hendrickson \& Au, 2003; Howell, 1999). As noted by Demian \& Walters (2014),

"BIM has a core potential to foster significantly greater collaboration between project participants” (p.1163)

Increased organizational collaboration necessarily means an increased entwining of fortunes, although the contractual realities and new ways of working required to make BIM collaboration a reality are often overlooked. Current contractual terms predominating in the UK do not allow for this collective responsibility, but the UK government Cabinet Office has been instrumental in exploring new ways of improving the perceived inefficiencies of the UK construction industry through a number of construction trial projects (Cabinet Office, 2014). The Advance II project (a pseudonym) is one such trial project pioneering a new method of project delivery (IPI) that potentially facilitates enhanced BIM use. Young et al. (2016) state that alliancing is often considered at the top end of collaborative and relational contracting, but the Advance II project takes one step further by employing a single insurance policy that joins all principal parties together to achieve a mutual "best for project" outcome.

A significant amount of work has addressed BIM implementation on projects, its` setup and management. Miettinen and Paavola (2014) highlight the significance of the organizational change process resulting from BIM whilst Murphy (2014) considers BIM implementation as an innovative process. Arayici et al. (2011) point out that BIM implementation is complex where it involves competence training and new business models whilst Neto (2016) notes the extensive preparation, required, commenting, 
"BIM must be considered as a strategic process that involves organizational change and innovation, beyond technical aspects." (p.149)

This paper takes forward such views to examine their applicability and validity in a collaborative project context.

\section{RESEARCH METHOD}

The University of Reading was tasked by Innovate UK (IUK - a primary funder of innovative industry-led research) to examine the performance of the IPI model on a live construction project. A researcher was appointed to examine project performance over time, becoming embedded into project activities as much as possible (i.e. attending meetings; receiving team emails; accessing the Common Data Environment (CDE). The evidence presented in this paper was gathered by the researcher through the course of his work. Additionally, an interview with one of the two project Information Managers clarified the issues of significance relating to BIM mobilization on the project. The interview was conducted in the early construction phase as numerous suppliers were about to commence construction work. At the time of the interview, the BIM system had become operational.

\subsection{The Advance II project \& IPI}

Dudley College, a further education institute located in the UK West Midlands were actively seeking to procure a new facility to develop their vocational training programmes in construction skills. IPI offered Dudley College a fundamentally different way of procuring a new facility; IPI potentially facilitating greater collaboration and better results by bringing parties together as a virtual company working under a single insurance policy (Cabinet Office, 2013). The IPI model applies an integrated collaborative working approach to the design, delivery and fit-out phases of a construction project, including the adoption of a Project Bank Account, BIM and lean implementation practices. Under IPI, a project team is appointed at project inception, working under an Alliance Contract and working together under a shared single insurance policy. On Advance II, the project Alliance consisted of the client, the architect, civil \& structural engineers, constructor, engineering services specialist contractor and project co-ordinator. A single (third party assured) insurance policy covers risks associated with the delivery of the project; each Alliance member agreeing a gain-share benefit and capped pain-share risk depending on overall project outcome. Partners work together collaboratively under a shared "no blame/no claim" cultural ethos to enhance best for project outcomes. For further information about the IPI procurement model see Cabinet Office $(2013 ; 2014)$. The paper now proceeds to describe what work was done on Advance II regarding BIM.

\section{BIM MOBILIZATION ON ADVANCE II}

\subsection{Initial Work}

Use of BIM was important for the project from the start: the client making BIM level 2 a requirement and the project team wanting the BIM model to be the single system through which all information would flow. Initial BIM roles and responsibilities were defined in the early design phase period as a comprehensive BIM strategy was agreed. The most experienced BIM Alliance partner undertook BIM management work as a sub-group was 
formed to specifically address BIM issues; each Alliance partner nominating a BIM champion to sit on the sub-group and coordinate issues from that partner`s perspective. The BIM group reported directly to the Alliance Board, composed of senior representatives of each Alliance partner. The Information Manager reflected in interview that the initial Alliance selection process should have been more robust in BIM terms,

"Really, we should have had an EIR (Employer Information Requirement) when the Alliance was selected. That would have set the requirements for capability around BIM and information delivery. All members should have done a pre-contract BIM Execution Plan (BEP) to say "this is how we will respond to the Employer Information Requirements (EIR)”.

However, part of the project strategic brief was a stated need for advanced BIM use on Advance II, for both teaching and curriculum development, with the selected partners advising on what was considered leading practice, although this did not translate into a specific stated EIR requirement at the selection stage.

BIM learning and education became a significant issue on the project; pre-contract BEPs would have indicated where BIM capability shortfalls within the team occurred. A BEP was formulated alongside an evolving EIR as the client clarified their needs through Plain Language Questions (PLQ)s, 'Soft Landings' performance criteria, an Education Information Model (EIM) and operations/maintenance requirements to be delivered within the Asset Information Model (AIM). Further meetings clarified needs in terms of design and information: a 3D model with a link to Operations \& Maintenance documentation being a stated requirement. It was also agreed that a specific Soft Landings delivery plan would be developed so that building information could be tailored to the College's preferred maintenance strategy. Throughout this phase, the Alliance worked intensively on multiple issues, including planning application; refinement of the cost plan; design development; thermal modelling and evolution of a procurement strategy. All these activities were challenging, as project partners were working collaboratively together for the first time. Although not in the forefront of activities, the importance of BIM remained an ever-present theme at meetings.

At this time, the BIM group realised that a new plan of work was needed to be devised for the project (the commonly referenced RIBA (2013) work stages being inappropriate for an IPI project. The Information Manager later commented,

"As a virtual business, things like roles, responsibilities, hierarchy and processes for authorization should have been defined first and BIM then built around it. But we had to define BIM implementation from a theoretical point of view in terms of how it should be done. We had to deconstruct the logic first and make sense of that because that tells you where the information exchanges need to be."

It was clear that the scale of mobilizing BIM on the IPI project had not been appreciated enough at a strategic level at project commencement; the BIM sub-group consequently needing to work very hard to optimize BIM as the project gathered momentum. 


\subsection{Interoperability \& Collaboration}

The 4Projects collaboration tool was mobilized as the selected CDE: the central hub by which information is shared and circulated amongst the project parties. A 4D model was used that linked the construction programme with the building model (this method being noted by Mahalingam et al., 2010). Professional specialists used their own software packages as normal (e.g. Tekla Structures for steel fabrication; Revit for architectural \& structural design) as Asta PowerProject was used for integrated programme management. Partners started to feed their separate design data into an evolving $4 \mathrm{D}$ model as a fortnightly production delivery cycle was formulated (figure 1) by the BIM Group to enable regular information updates to be added to the model and project integrated programme.

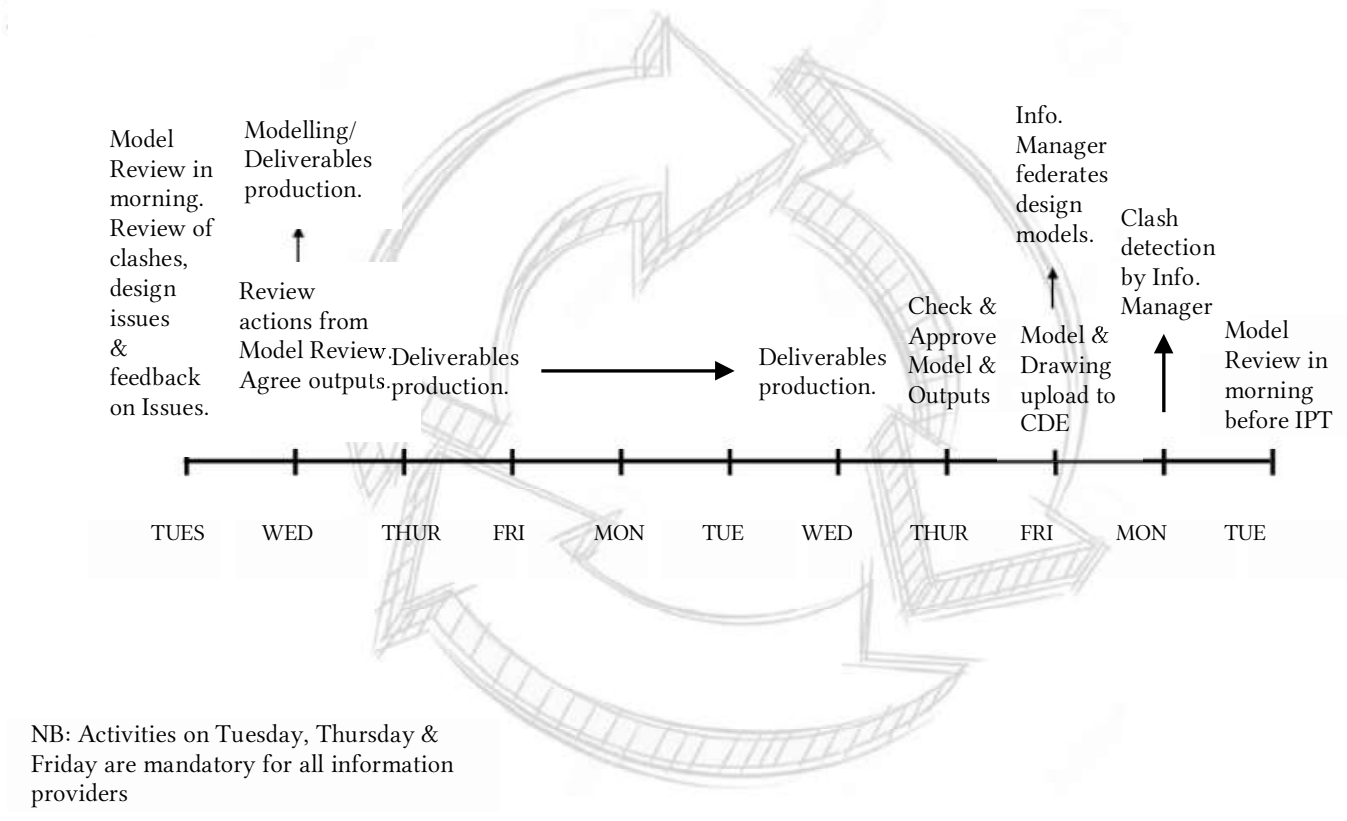

Figure 1Information Production Delivery Cycle

This synchronised delivery of information was argued to be imperative for BIM success; it being envisaged that the BIM model would mature as more suppliers joined the project, contributing their package programmes and information. The geometry of the BIM model would therefore more accurately reflect package sequences within the overall construction programme.

A "Build in a Day" workshop brought Alliance partners together to review the model and communicate with each other easily and collaboratively. The team were subsequently instructed to feed further detail to the model in terms of sequencing of events, the Information Manager commenting,

"At this stage we are not looking for precise co-ordinated build sequences, just an educated guess at what the sequence might be so we can add granularity to the animation. We can't expect to have the final answer prior to appointing the relevant suppliers. However, we can start to set down what 'we' think 'our' preferred sequence may be to meet the overall 
programme. This way, when we sit down with the relevant suppliers, we can show them the animation to show what our intent is."

Through the bi-weekly information delivery cycle, the Alliance endeavoured to evolve the design model in line with the project programme as more work focused upon the potential use of BIM on the project; it being argued that benefits would become evident over time, with information transfer, storage, accessibility and information redundancy all potentially benefitting. The IPI model enabled this close collaboration to occur around the evolving BIM model, and whilst collaboration can occur under "traditional" models of procurement, with IPI, collaboration is continuous, extends to a wider team and is more transparent.

\subsection{Scope of Work}

The amount of work required to make BIM effective became increasingly clear as the project progressed. For example, to take advantage of innovative procurement methods (and to deliver information in the most efficient way possible), an ongoing review of information requirements for separate work packages was required; the information requirements of each separate work packages being unique. With IPI Policy inception, the Information Manager reminded personnel of the need for collective coordinated information sharing/production activities: the correct timing/cycling of information being critical for effective model based information delivery. The Information Manager also informed the team that his role was to manage the CDE and not to upload items to it, advising the team to read the 4Projects guidance document and the project BEP. Evidently, the new work processes were particularly challenging for Alliance members as each partner was also engaged in other projects operating under more traditional procurement and delivery routes. The Information Manager later commented,

"Trying to get the team to do proper information delivery \& management has been difficult. This is because careful thought is required to establish what the minimum information required is and this is harder than normal for them. The industry is so resistant to change to all embracing new methods of working."

As noted, training of Alliance partners with low BIM knowledge was an issue of significance, with literature (i.e. a 4Project guide; a BEP) being produced to tell people what to do in a way that provided education so they understood the difference between a Revit 3D model and a Project Information Model (with consistent language used throughout). Commenting retrospectively, the Information Manager said,

"I think core capability around BIM tools has cost the project. Inefficiency of the information production and then facilitating people`s learning and training to try and get them up to speed. There has been a lot of time resource spent and that wasn`t predicted accurately enough in the initial people resource costs."

By late October 2016, the project had entered the early construction phase, with the structural frame being erected on-site. When interviewed, the Information Manager commented about the BIM state-of-play, but also the impact of working under an IPI procurement model,

"Collaboration has been good. We have one set of information and all files are named in accordance with the standard which is greatly assisting operations downstream. But 
people`s understanding is not there yet. But without IPI, we would not be where we are. Without IPI, we will never realise the full potential of BIM because you have a contractual line halfway through the process then you get a fragmented information exchange."

\section{DISCUSSION}

Several issues emerge from the paper. The amount of work required to plan, set-up and manage a BIM system in a collaborative project context is considerable. On Advance II, this was underestimated; only the dedicated input of the partner with advanced BIM knowledge enabling a federated BIM model, an information input cycle, a BEP and clear plan of action to be devised. There were consequential impacts on labour, time and training for the project. Strategically, although the importance of BIM had been recognized early, the organizational impact and effects of process integration had not been appreciated enough. These insights lead the paper to echo the findings of scholars such as Neto (2016), Arayici et al. (2011) and Merschbrock and Munkvold (2012) that the organizational aspects of BIM are a fertile area upon which to direct the lens of academic enquiry.

The importance of alliancing contracting (such as IPI) for BIM optimization also emerges from the paper. BIM requires free movement of information between parties and this is only achievable if contractual barriers are removed. However, even in a fully collaborative project setting, the "burden of BIM" will fall more heavily upon certain project partners. On Advance II, although positive use of BIM enabled the project to overcome some of those professional and organizational barriers identified by Kahler et al. (2016) to the delivery of a digitally enabled project, the challenge of ensuring suppliers also embrace BIM was noted as significant. Resistance to change behaviours from suppliers is likely to remain an obstacle to BIM evolution unless they are positively embraced by projects. On Advance II, the Alliance are currently discussing new and innovative methods of engaging suppliers to ensure they utilise the BIM system.

\section{CONCLUSION}

The paper explored work done on the Advance II project with regards to BIM mobilization. The findings indicate that fundamental to BIM achievements is the IPI model that enables enhanced collaboration and communication to occur. However, the work and organizational time required to set it up was underestimated, as were associated training and labour costs. Strategically, a holistic BIM system requires full process integration from Alliance partners rather than a tweak to information management processes. Such an organizational change process is challenging when other projects are being managed under more traditional ways of working. As the first trial of IPI in the UK, Advance II is generating new knowledge and learning in multiple spheres of construction project activity, including cost and risk management, procurement, leadership and design development. It is envisaged that further insights regarding BIM use on Advance II will become apparent as the project evolves, to be duly reported by the UoR and Innovate IUK.

\section{REFERENCES}

Arayici, Y., Coates, P., Koskela, L., Kagioglou, M., Usher, C. \& O`Reilly, K. (2011). Technology adoption in the BIM implementation for lean architectural practice. Automation Construction, 20(2), pp. 189-195.

Cabinet Office (2014). New models of construction procurement. Cabinet Office, London. 
Cabinet Office (2013). The Integrated Project Insurance (IPI) Model. Project Procurement and Delivery Guidance. Government Construction Strategy 2011.

Demian, P \& Walters, D (2014). The advantages of information management through building information modelling, Construction Management and Economics, 32(12), pp. 1153-1165.

Eastman, C M, Teicholz, P, Sacks, R and Liston, K (2008). BIM Handbook: a guide to building information modelling for owners, managers, designers, engineers and contractors, models of construction procurement. Wiley, Hoboken, NJ.

Hendrickson, C and Au, T (2003). Project management for construction: fundamental concepts for owners, engineers, architects and builders, 2nd ed., Prentice Hall, Pittsburgh, PA.

Howell, G A (1999). What is lean construction: 1999. Paper presented at the 7th Annual conference of the International group for lean construction, 26-28 July, Berkeley, CA. Hui, S (2013). Research on construction contract under BIM conditions, Journal of Applied Sciences, 13(9), pp.3926-3930.

Gardiner, J (2016). Have you seen the BIM deadline? Building Magazine (Agenda: BIM special), 22-25.

Kahler, D., Brown, D, Watson, J. (2016). "Delivering projects in a digital world" In: Proc. 24th Ann. Conf. of the Int'l Group for Lean Construction, Boston, MA, USA, sect.1 pp. 3342.

Mahalingam, A, Kashyap, R and Mahajan, C (2010). An evaluation of the applicability of 4D CAD on construction projects, Automation in Construction Management, 19(2), pp. 148-159.

Miettinen, R. and Paavola, S. (2014). Beyond the BIM utopia: approaches to the development and implementation of building information modelling, Automation in Construction, 43, pp. 84-91.

Merschbrock, C. and Munkvold, B.E. (2012). A research review on building information modelling in construction - an area ripe for IS research, Communications for the Associations of Information Systems, 31(1), p.10.

Murphy, M.E. (2014). Implementing innovation: a stakeholder competency-based approach for BIM, Construction Innovation, 14(4), pp.433-452.

Neto, J.P. (2016). "Approach for BIM implementation: a vision for the building industry.". In: Proc. 24th Ann. Conf. of the Int'I Group for Lean Construction, Boston, MA, USA, sect.1 pp. 143-152.

RIBA (2013). RIBA job book. RIBA Publishing, London.

Young, B.K., Hosseini, A. and Laedre, O. (2016). "Project alliances and lean construction principles". In: Proc. 24th Ann. Conf. of the Int 'l Group for Lean Construction, Boston, MA, USA, sect.3 pp. 33-42. 